\title{
ARTICLE OPEN Inhibiting hydrogen embrittlement in ultra-strong steels for automotive applications by Ni-alloying
}

\author{
Sung Jin Kim ${ }^{1}$, Eun Hye Hwang ${ }^{1}$, Jin Sung Park ${ }^{1}$, Seung Min Ryu ${ }^{1}$, Dae Won Yun ${ }^{2}$ and Hwan Goo Seong ${ }^{3}$
}

With the stricter international regulations on $\mathrm{CO}_{2}$ emissions, fuel economy, and auto-safety, the application of novel materials with both higher strength and lower weight is becoming a major technical issue in automotive industries. Among the various lightweight concepts, ultra-strong GIGA STEEL with a tensile strength of more than $2 \mathrm{GPa}$ is a major breakthrough in light of the remarkable weight reduction of vehicle without a decrease in auto-safety. Despite the outstanding mechanical performance, hydrogen embrittlement induced by aqueous and/or atmospheric corrosion is a serious problem that has restricted the application of steel to auto-parts. This study reports that such a critical challenge can be overcome by Ni-alloying, which leads to a lower cathodic reduction rate on the steel surface and slower $\mathrm{H}$-infusion kinetics in the steel matrix. In contrast to the beneficial effects of Ni-alloying, conflicting results can be obtained when steel with a higher Ni content ( $\geq 1 \mathrm{wt} . \%)$ is exposed to neutral-corrosive environments, but the results have not been verified using conventional metallurgical approaches. This paper proposes a mechanism for these conflicting results, and provides a new and economic strategy for superior resistance to corrosion-induced hydrogen embrittlement, by making optimal use of Ni-alloying of ultra-strong steel.

npj Materials Degradation (2019)3:12; https://doi.org/10.1038/s41529-019-0074-5

\section{INTRODUCTION}

Considering that the material cost of a car accounts for $\sim 50 \%$ of the total car price (Manufacturing: 30\%, Balance: R\&D and others), ${ }^{1}$ there is increasing demand for materials with much higher strength and lower weight. Ultra-strong GIGA STEEL developed recently is three times stronger than $\mathrm{Al}$, a typical non-ferrous metal used in auto-parts. Therefore, much thinner parts would be needed to produce lighter but safer and more economical cars. ${ }^{2,3}$ In general, increasing the tensile strength of ferrous alloys can be achieved by metallurgical strategies, such as grain refinement and/or precipitation hardening. In addition, a much higher tensile strength (over $2 \mathrm{GPa}$ ) can be achieved practically and economically using a higher $\mathrm{C}$ content in ferrous alloys, leading to the precipitation of iron carbides $\left(\varepsilon-\mathrm{Fe}_{2.4} \mathrm{C} / \mathrm{Fe}_{3} \mathrm{C}\right)$ with a low $\mathrm{H}$ overvoltage. $^{4,5}$ Furthermore, carbides are metallic conductors ${ }^{5,6}$ and act as a cathode, ${ }^{5,7}$ resulting in selective dissolution of the matrix. For this reason, it is generally accepted that an increase in the strength of steels is accompanied essentially by a substantial decrease in the resistance to aqueous/atmospheric corrosion ${ }^{5,8}$ as well as $\mathrm{HE}^{4,9-11}$

HE of a variety of ferrous alloys has been investigated extensively, ${ }^{11-15}$ but most experimental approaches in these studies focused primarily on the mechanical degradation of specimens charged fully with $\mathrm{H}$ by applying an extremely high cathodic current in an aqueous solution. ${ }^{14-16}$ Although a number of researchers have provided significant insights into $\mathrm{H}$-trapping and the resulting cracking behaviors of ferrous alloys, their experimental approaches using electrochemical $\mathrm{H}$-charging in aqueous solutions exclude corrosion reactions on the alloy surface. On the other hand, the surface properties related to aqueous corrosion become predominant over the internal metallurgical effects under mild and near-neutral environments with low $\mathrm{H}$-concentrations, to which automotive steels are normally exposed. From these perspectives, conventional experimental methods, involving severe $\mathrm{H}$-charging and subsequent simple mechanical testing, are inadequate practically. Therefore, alloy design for ultra-strong automotive steel with superior resistance to $\mathrm{HE}$ has not been optimized, and the precise role of alloying elements in this resistance is not completely understood. Among the elements, the precise role of $\mathrm{Ni}$ in the $\mathrm{H}$-absorption/ embrittlement of steels is controversial. ${ }^{17-21}$ The beneficial effects of $\mathrm{Ni}$-addition have been reported ${ }^{17,18}$ and the mechanism is based primarily on the microstructural modifications induced by $\mathrm{Ni}$. On the other hand, adverse effects ${ }^{19,20}$ or no effects ${ }^{21}$ have also been reported. Nevertheless, the effects of Ni-alloying on the $\mathrm{H}$ reduction and uptake kinetics on the surface have not been clarified. The aim of this study was to gain deeper insights into corrosion-induced HE from two perspectives: surface properties and internal H-diffusion behaviors. Based on this, an effective strategy for the production of much stronger steels with superior resistance to $\mathrm{HE}$ was developed by the optimal use of Ni-alloying.

\section{RESULTS AND DISCUSSION}

Microstructure

Figure 1 presents the microstructure of the medium C (0.43 wt.\%) ultra-strong steel with a tensile strength of $2 \mathrm{GPa}$. Electron backscatter diffraction (EBSD) and transmission electron microscopy (TEM) showed that the representative microstructure was composed of lath-type martensite with fine need-shaped carbides

\footnotetext{
${ }^{1}$ Department of Advanced Materials Engineering, Sunchon National University Jungang-ro, Suncheon, Jeonnam 540-742, Republic of Korea; ${ }^{2}$ Korea Institute of Materials Science (KIMS), 797 Changwondaero, Seongsan-gu, Changwon 642-831, Republic of Korea and ${ }^{3}$ POSCO Technical Research Laboratories, Kumho-dong, Gwangyang, Jeonnam 545-090, Republic of Korea

Correspondence: Sung Jin Kim (sjkim56@scnu.ac.kr)
}

Received: 27 September 2018 Accepted: 28 January 2019

Published online: 21 March 2019 

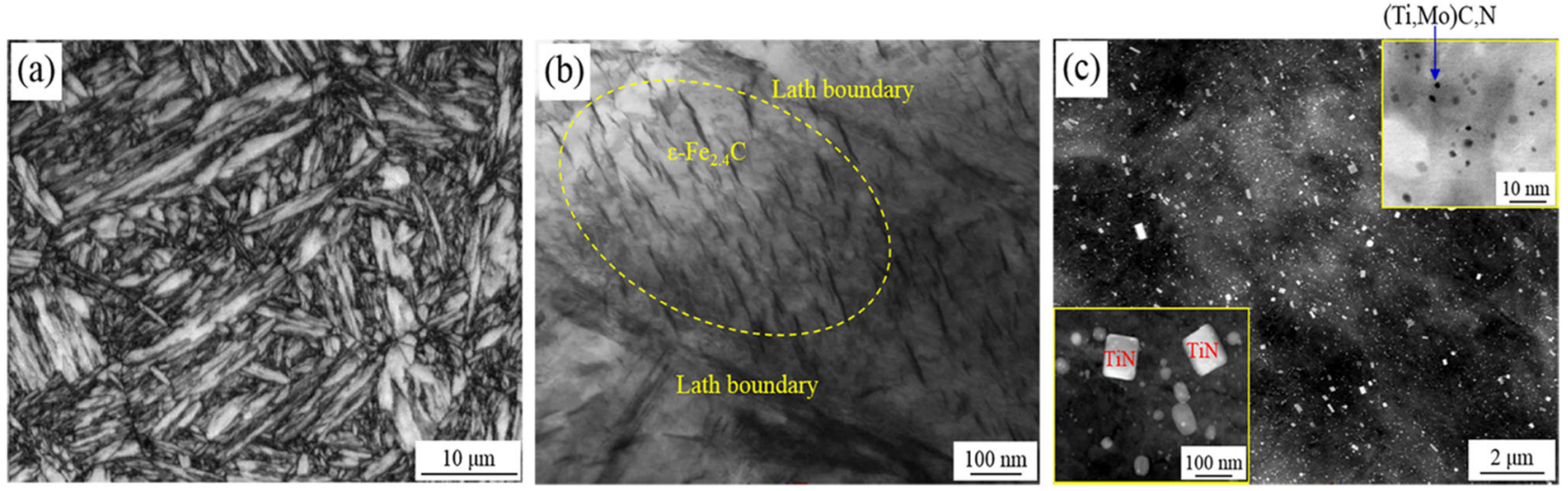

Fig. 1 a Microstructure with tempered martensite obtained by an image quality (IQ) map constructed from electron backscatter diffraction (EBSD). b TEM image showing distribution of $\varepsilon-\mathrm{Fe}_{2.4} \mathrm{C}$ carbides in a martensite lath in higher magnification. $\mathbf{c}$ TEM image of the precipitates obtained using the extraction replica technique

\begin{tabular}{|lllllllll|}
\hline \multicolumn{7}{|c}{ Table 1. Chemical composition of the tested samples (in weight-\%) } \\
\hline Specimen & $\mathrm{C}$ & $\mathrm{Mn}$ & $\mathrm{Cr}$ & $\mathrm{Mo}$ & $\mathrm{Cu}$ & $\mathrm{Ni}$ & $\mathrm{Fe}$ \\
\hline $\mathrm{N} 1$ & $0.4-0.5$ & $1.0-1.5$ & $<0.2$ & $<0.2$ & $<0.1$ & $0.1-0.3$ & Bal. \\
N2 & $0.4-0.5$ & $1.0-1.5$ & $<0.2$ & $<0.2$ & $<0.1$ & $0.6-0.8$ & Bal. \\
N3 & $0.4-0.5$ & $1.0-1.5$ & $<0.2$ & $<0.2$ & $<0.1$ & $1.0-1.2$ & Bal. \\
\hline
\end{tabular}

$\left(\varepsilon-\mathrm{Fe}_{2.4} \mathrm{C}\right.$ is considered a transition carbide that precipitates during low temperature tempering ${ }^{22,23}$ ) along the lath. From TEM observations using the extraction replica technique, two types of precipitate, which are characterized as coarse TiN and fine (Ti,Mo) $\mathrm{C}$, respectively, were distributed uniformly throughout the matrix. It is noteworthy that the presence of fine carbides with a nanometer size may not only give rise to significant strengthening ${ }^{24,25}$ by hindering dislocation motion or pinning effect, but also act as $\mathrm{H}$-traps, ${ }^{26-28}$ leading to slower kinetics of $\mathrm{H}$-diffusion.

Surface characteristics of the bare steel samples, and their effects on the electrochemical behaviors

As listed in Table 1, three different levels of $\mathrm{Ni}(0.1-0.3,0.6-0.8$, and 1.0-1.2 $\mathrm{wt} \%$ ) were added to the tested ultra-strong steel. The specimens are simply referred to as N1, N2, and N3, respectively.

Figure 2a presents the auger electron spectroscopy (AES) depth profile of the surface of N3, showing a metallic Ni enriched layer, approximately $4 \mathrm{~nm}$ in thickness, beneath the surface oxide film. The two controlling factors, $\mathrm{H}$-generation by a cathodic reduction reaction $\left(\mathrm{H}^{+}+\mathrm{e}^{-} \rightarrow \mathrm{H}\right)$ on the surface and $\mathrm{H}$-penetration through the surface, were analyzed separately to determine the surface barrier effect by the preferential enrichment of $\mathrm{Ni}$. As shown in Fig. 2b, N3 exhibited a higher polarization resistance $\left(R_{p}\right)$ than N1, as measured under a cathodic bias potential in the electrochemical impedance spectroscopy (EIS) test, suggesting that $\mathrm{H}$ generation by a cathodic reduction reaction is suppressed on the surface enriched by $\mathrm{Ni}$. For the other controlling factor, Fig. 2c presents the electrochemical permeation test results showing the $\mathrm{H}$-penetration behaviors obtained from $\mathrm{H}$-permeation through the thin steel membrane. $\mathrm{H}$-penetration through the $\mathrm{Ni}$ enriched layer was more restricted, as illustrated in the lower H-diffusivity $\left(D_{\text {app }}\right)$ and steady-state permeation current $\left(J_{\mathrm{ss}}\right)$ of N3. Faster H-diffusion kinetics is normally expected in N3 considering that Ni-addition leads to a decrease in the amount of iron carbides acting as $\mathrm{H}$ traps $^{29,30}$ in the steel matrix (refer to Supplementary Fig. 1, in accordance with previous results ${ }^{17,31}$ ). Nevertheless, the much slower diffusion kinetics of N3 means that the infusion of nascent $\mathrm{H}$ into the steel is prevented by the thin $\mathrm{Ni}$ enriched layer on the

surface. These results are in accordance with previous studies, ${ }^{32}$ which reported the beneficial effect of $\mathrm{Ni}$ on the resistance to $\mathrm{HE}$ of high-strength steels with a tensile strength of $1.5 \mathrm{GPa}$.

Corrosion tests and an analysis of the corrosion products formed on the surfaces of tested samples

The surface inhibiting effects imparted by $\mathrm{Ni}$, which were observed in bare steel under electrochemical treatments, persisted in the neutral aqueous environment of 3.5\% $\mathrm{NaCl}$ even after longer exposure times. Under long-term immersion conditions, a high corrosion resistance could be attributed primarily to the corrosion products with protective characteristics, formed on the surface. A previous study ${ }^{33}$ reported that the corrosion scale formed on high-strength carbon steel exposed to a neutral solution containing chloride ions has a bi-layer structure composed mainly of an adhesive inner-layer of $\mathrm{Fe}_{3} \mathrm{O}_{4}$ and a non-adhesive outer- layer of $\gamma$-FeOOH. Although $1.2 \mathrm{wt} \% \mathrm{Ni}$ was added to the ultra-strong steel, the nature of the corrosion scale formed on the surface was not changed and the difference in the structure of the inner scale could not be identified by X-ray diffraction (XRD), as shown in Supplementary Fig. 2. As shown in Fig. 3a, however, the weight loss per unit area decreased linearly with increasing $\mathrm{Ni}$-addition to the steel. Several mechanisms for the beneficial effects of $\mathrm{Ni}$-addition in minute quantities to the steel have been proposed: partial substitution of $\mathrm{Ni}$ atoms into the Fe-sites of $\mathrm{Fe}_{3} \mathrm{O}_{4}$ to form $\mathrm{Fe}_{3-\mathrm{x}} \mathrm{Ni}_{x} \mathrm{O}_{4}{ }^{34}$ formation of a protective amorphous layer in the rust, ${ }^{35}$ and the refinement of rust particles by increasing the atomic level heterogeneity in rust. ${ }^{36}$ Although it may not be possible to elucidate the precise mechanism, the results suggest that the beneficial effect of $\mathrm{Ni}$-addition on the long-term corrosion resistance is closely associated with the denser and finer rusts $\left(\mathrm{Fe}_{3} \mathrm{O}_{4}\right)$ enriched with $\mathrm{Ni}$ formed on the steel surface, as shown in the cross-sectional observations and EDS spectrum in Fig. 3b, c, respectively. Supplementary Fig. 3 shows the results of depth profile analysis obtained by glow discharge spectroscopy (GDS); $\mathrm{Ni}$ is enriched in the thinner scale formed on N3 compared to N1. A higher open circuit potential (OCP) and lower anodic dissolution rate on the N3 surface, as shown in the potentiodynamic polarization measured after $3 \mathrm{~h}$ pre-exposure to a $3.5 \% \mathrm{NaCl}$ solution (Fig. 3d), can also be understood in the same context.

Slow strain rate test (SSRT) and surface morphology observation to evaluate the resistance to corrosion-induced $\mathrm{HE}$

One of the important findings in this study was the conflicting results of the $\mathrm{Ni}$-alloying effect on corrosion-induced $\mathrm{HE}$. In contrast to expectation based on the pre-described beneficial 
(a)

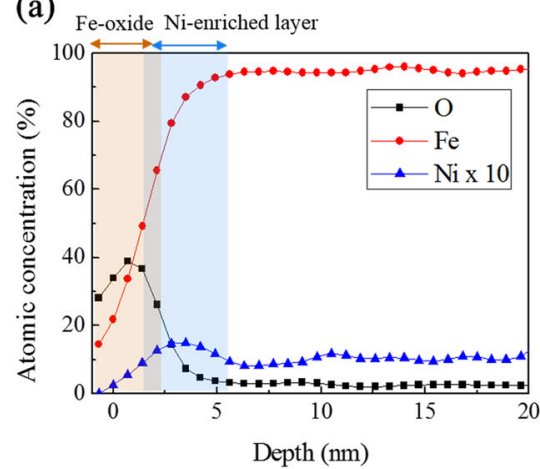

(b)

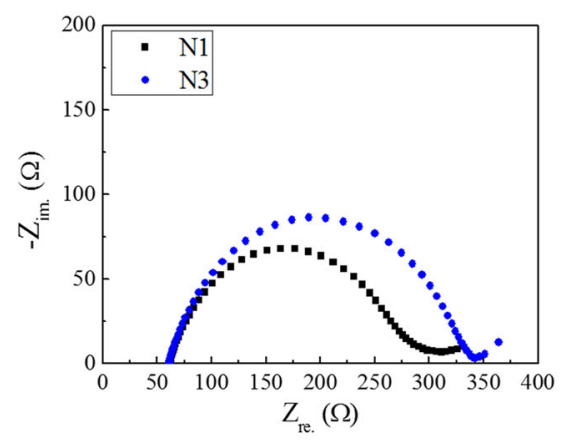

(c)

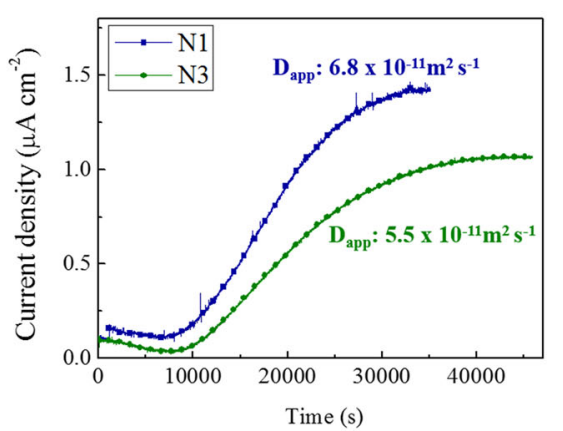

Fig. 2 a Compositional depth-profile, as analyzed by AES, of the as-polished N3. b EIS Nyquist plots of N1 and N3 measured immediately after immersion in a Walpole solution of $0.2 \mathrm{M} \mathrm{CH}_{3} \mathrm{COONa}+0.185 \mathrm{M} \mathrm{HCl}$. c Electrochemical hydrogen permeation transients with apparent $\mathrm{H}-$ diffusivity values $\left(D_{\text {app }}\right)$, measured under an applied cathodic current density of $1 \mathrm{~mA} \mathrm{~cm}{ }^{-2}$ in a $3.5 \% \mathrm{NaCl}+0.3 \% \mathrm{NH}_{4} \mathrm{SCN}$ solution in the $\mathrm{H}$ charging side, and applied anodic potential of $270 \mathrm{mV}_{\mathrm{SCE}}$ in a $0.1 \mathrm{M} \mathrm{NaOH}$ solution in the H-detection side

effects of Ni-alloying, a significant decrease in elongation with increasing Ni content was observed from the SSRT conducted in a neutral aqueous solution, as shown in Fig. 4a. More pits as a type of localized corrosion, which form normally at the 2nd-phase particles characterized primarily as (Al,Ca)-based oxide, were observed on the N3 surface in a neutral solution (Fig. 4b), and vice versa in an acidic solution. Considering these facts, the adverse effects of $\mathrm{Ni}$-alloying are closely related to localized corrosion induced by $\mathrm{Ni}$-depletion around the local heterogeneities (2nd-phase particles) acting as stress intensifiers under an applied stress, which increase the susceptibility of N3 to corrosioninduced HE. The localized corrosion behavior presented in this study could be understood in a similar context to the discontinuities of the passive film around the 2nd-phase particles, and preferential pitting corrosion in the particles on the surface of stainless steel. ${ }^{37}$ The $R_{p}$ value obtained by EIS shortly before fracture of the specimen can be an electrochemical index indicating the surface state. The $R_{p}$ values measured under neutral condition were marked in Fig. $4 \mathrm{~b}$, and their Nyquist plots can be found in Supplementary Fig. 4. N3 showed a lower $R_{p}$ in a neutral solution, which suggests that N3 has a higher pit density on the surface. In contrast to localized corrosion in the neutral solution, local pits or corrosion products were not observed preferentially in the Walpole solution. This may be caused by the corrosion process in an acidic solution being controlled primarily by the strong anodic dissolution rate and resulting uniform corrosion. Because the diffusible $\mathrm{H}$-content is regarded as one of the factors for $\mathrm{HE}$, the contents in the tested steels were measured by thermal desorption spectroscopy (TDS), and they can be found in Supplementary Fig. 5. The results showed that N1 has a much higher diffusible H-content than N3 when measured in an acidic environment. This is understandable from the SSRT result (i.e. a comparatively lower elongation level of N1) in Fig. 4a. On the other hand, the $\mathrm{H}$-contents were similar in $\mathrm{N} 1$ and $\mathrm{N} 3$ and extremely low, which were measured under neutral conditions, suggesting that the significant decrease in the total elongation of N3 under neutral conditions may be due primarily to the local stress concentration in the pits formed by localized corrosion around the 2 nd-phase particles with $\mathrm{Ni}$-depletion. Although the $\mathrm{H}$ entry mechanism changes according to the environment to which the specimen is exposed, and $\mathrm{H}$ can be infused in the steel by a hydrolysis reaction ${ }^{38,39}$ following local acidification when exposed to a neutral environment, $\mathrm{H}$ infuses in extremely small amounts and may not be the predominant factor for $\mathrm{HE}$, at least in this case.

$\mathrm{Fe}^{2+}+2 \mathrm{H}_{2} \mathrm{O} \rightarrow \mathrm{Fe}(\mathrm{OH})_{2}+2 \mathrm{H}^{+}$

Therefore, the decrease in HE resistance of N3 evaluated by SSRT can be estimated more accurately by the extent of local corrosion that appears in the form of $R_{p}$. Figure 5 presents a schematic illustration of the proposed corrosion mechanism in the two corrosive media. Anodic and cathodic sites were distributed throughout the surface of specimen exposed to the acidic solution. On the other hand, when the specimens were exposed to a neutral solution, anodic steel dissolution occurred preferentially around the 2nd-phase particle with $\mathrm{Ni}$-depletion, leading to localized corrosion.

Considering the diagram (Supplementary Fig. 6) showing the strain loss rate of $\mathrm{N} 1, \mathrm{~N} 2$, and $\mathrm{N} 3$ in a neutral solution, the threshold $\mathrm{Ni}$-content in which the detrimental effect of $\mathrm{HE}$ had been reached was more than $0.8 \mathrm{wt} . \%$.

SSRT and fracture surface observation to evaluate the effects of $\varepsilon$ $\mathrm{Fe}_{2.4} \mathrm{C}$ on $\mathrm{HE}$

Another possible mechanism explaining the conflicting results of $\mathrm{Ni}$ alloying is based on the slower $\mathrm{H}$-effusion kinetics from $\varepsilon-\mathrm{Fe}_{2.4} \mathrm{C}$ distributed in the microstructure. $\varepsilon-\mathrm{Fe}_{2.4} \mathrm{C}$ is considered to be a strong $\mathrm{H}$-trap with a high $\mathrm{H}$-binding energy that partially immobilizes diffusible- $\mathrm{H}$ by the strong trapping capacity, ${ }^{12,23}$ suggesting that it can alleviate HE by suppressing the local $\mathrm{H}$ concentrations around potential crack sites, such as surface defects or local-pits. As mentioned above, $\mathrm{Ni}$-addition leads to a lower fraction of $\varepsilon-\mathrm{Fe}_{2.4} \mathrm{C}$ in the microstructure. Faster $\mathrm{H}$-diffusion to the triaxial stress field ${ }^{40-42}$ around surface defects is expected in steel with a higher $\mathrm{Ni}$ content. In contrast to the permeation experiment showing the slower diffusion of $\mathrm{H}$ reduced cathodically from the surface to the internal matrix of steel with a higher $\mathrm{Ni}$-content, the $\mathrm{H}$ mentioned in this case had been infused already in the steel matrix by local corrosion involving the hydrolysis reaction ${ }^{38,39}$ described in Eq. (1) and local acidification in the pits. Therefore, the faster diffusion of $\mathrm{H}$ can be expected in the matrix of steel with a higher Ni-content. To examine the effects of $\varepsilon$ $\mathrm{Fe}_{24} \mathrm{C}$ on $\mathrm{HE}$, a mechanistic study using SSRT after the two $\mathrm{H}$ charging processes was conducted, as summarized in Fig. 6. Figure $6 \mathrm{a}, \mathrm{b}$ shows the engineering stress-strain curves conducted on the two samples tempered for 30 and $45 \mathrm{~min}$, respectively, under different charging conditions. The HE-indices in the figures means the degree of mechanical degradation of pre-charged samples, which are quantified as follows:

$H E$ index $=\left(\omega_{\text {uncharged }}-\omega_{\text {charged }}\right) / \omega_{\text {uncharged }}$,

where $\omega_{\text {charged }}$ and $\omega_{\text {uncharged }}$ are the elongation reduction measured after $\mathrm{H}$-pre-charging and uncharging, respectively.

It is considered that an increase in tempering duration from 30 to $45 \mathrm{~min}$ results in a higher fraction of $\varepsilon-\mathrm{Fe}_{2.4} \mathrm{C}$. From Supplementary Fig. 7, however, there was negligible variation in the residual strain and dislocation density with increasing 
(a)

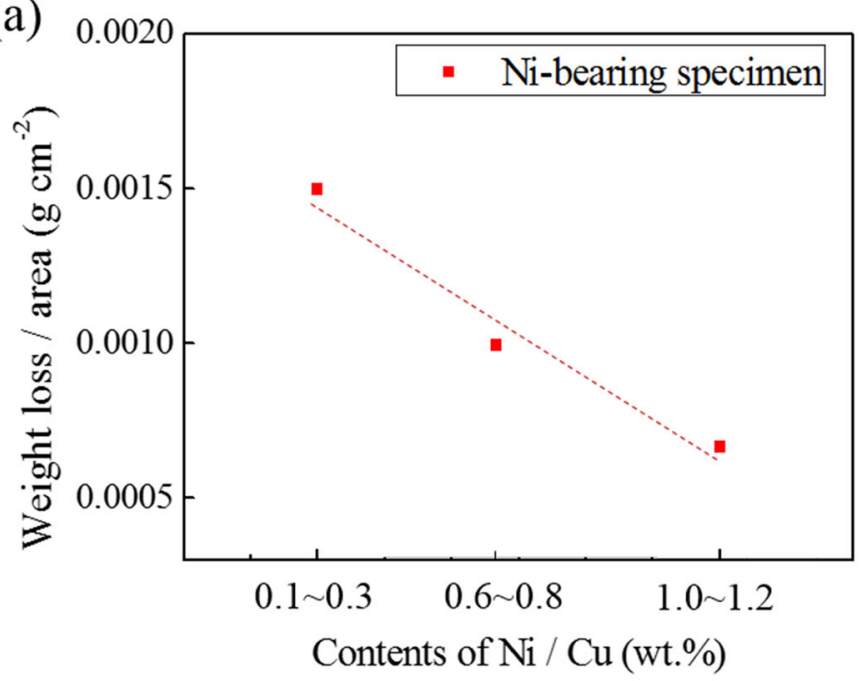

(b)
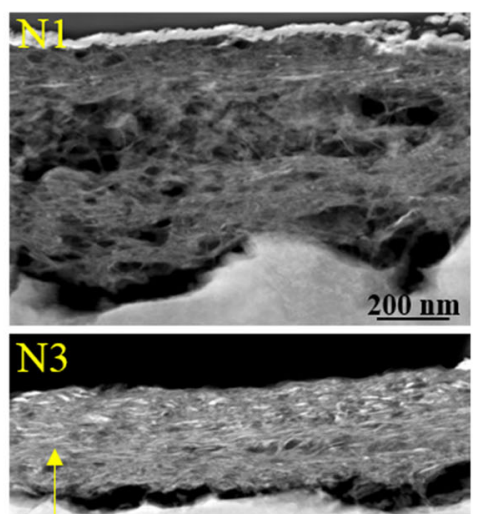

Scale (c)
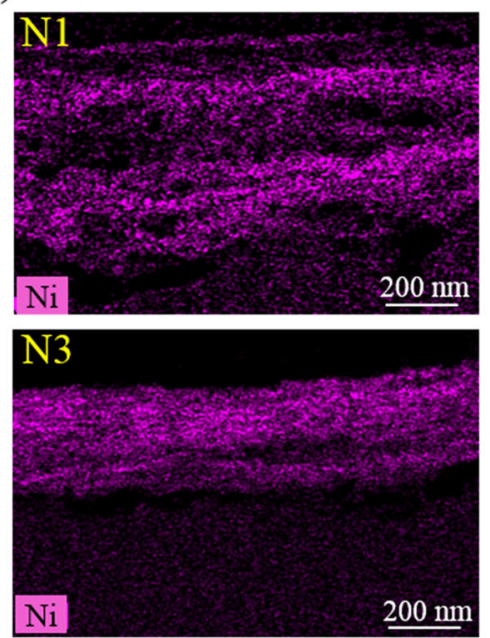

(d)

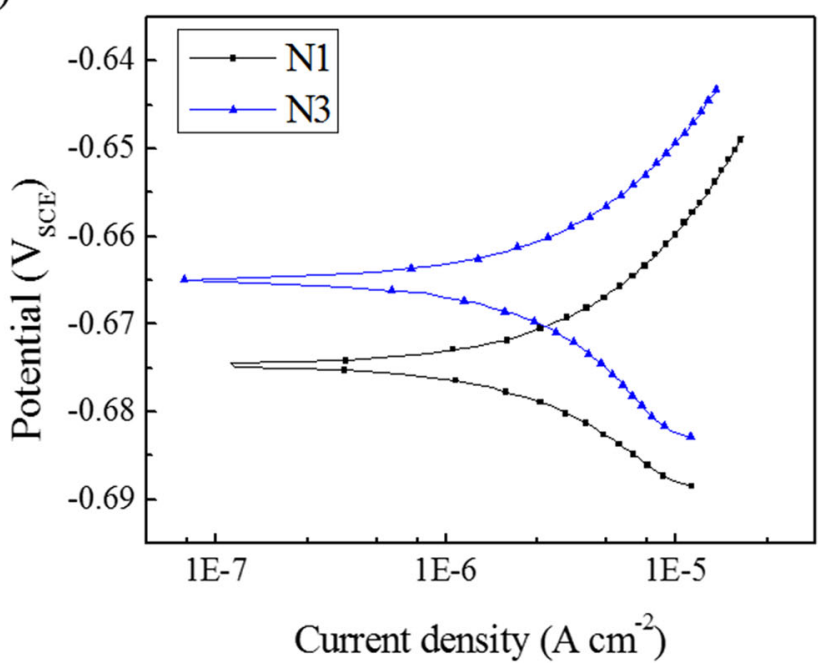

Fig. 3 a Weight loss measurements after the long-term immersion test for four weeks. b Cross-sectional morphologies of N1 and N3 observed after the long-term immersion test. c EDS-mapping analyses on the cross-sectional regions shown in (b). $\mathbf{d}$ Linear polarization resistance tests of $\mathrm{N} 1$ and $\mathrm{N} 3$, measured after $3 \mathrm{~h}$ pre-exposure in a $3.5 \% \mathrm{NaCl}$ solution

(a)

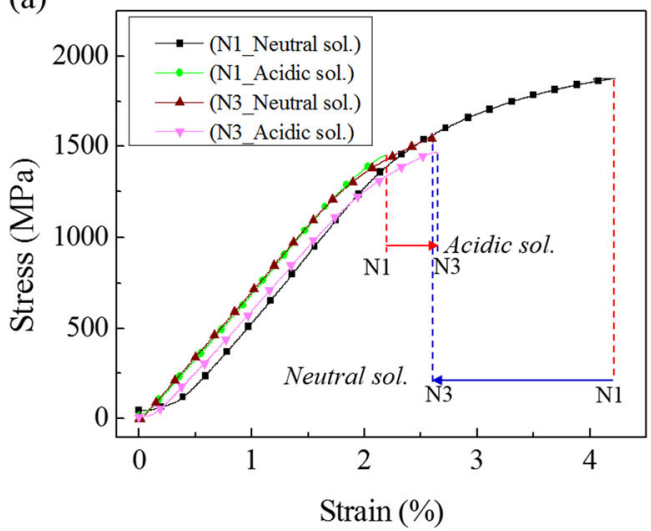

(b)

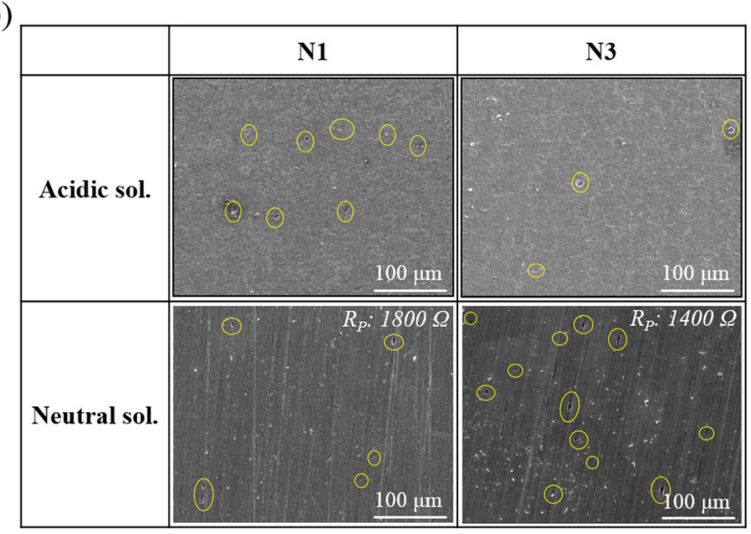

Fig. 4 a SSRT curves of $\mathrm{N} 1$ and $\mathrm{N} 3$ evaluated in a neutral sol. (3.5\% $\left.\mathrm{NaCl}+0.3 \% \mathrm{NH}_{4} \mathrm{SCN}\right)$ and acidic sol. $\left(0.2 \mathrm{M} \mathrm{CH} \mathrm{COONa}_{3}+0.185 \mathrm{M} \mathrm{HCl}\right)$ after $6 \mathrm{~h}$ pre-exposure in each solution. b Surface morphologies of N1 and N3 observed after immersion in the two solutions for $15 \mathrm{~h}$ 
- $2^{\text {nd }}$ phase particle

$\uparrow$ Preferential dissolution at around $2^{\text {nd }}$ phase particle in neutral sol. $\uparrow$ Anodic dissolution in acidic sol.

General dissolution in neutral sol.

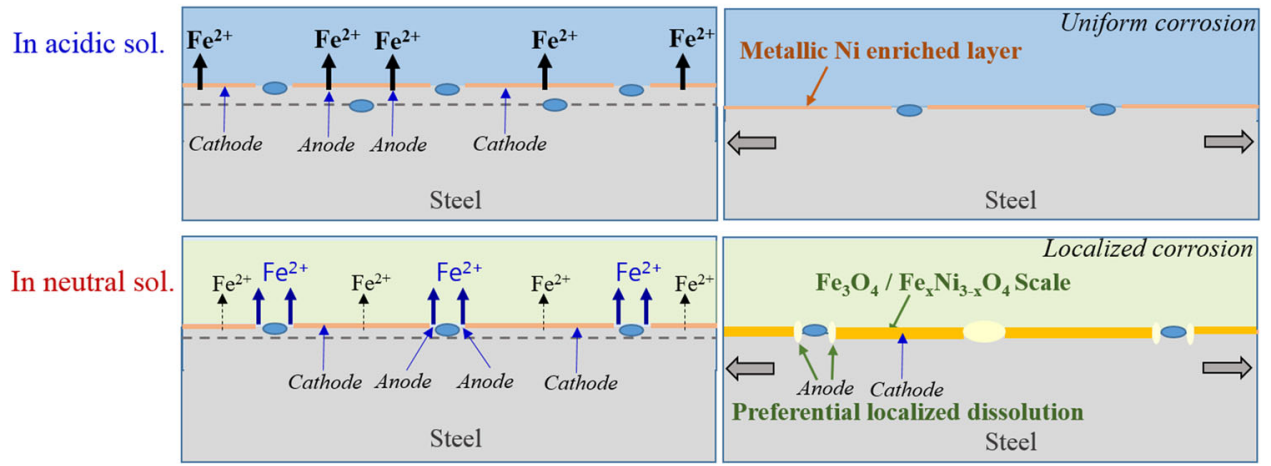

Fig. 5 Schematic diagram illustrating the proposed mechanism of the effects of Ni-alloying (1-1.2 wt.\% Ni) on the corrosion behaviors on the surfaces in the two corrosive media

(a)

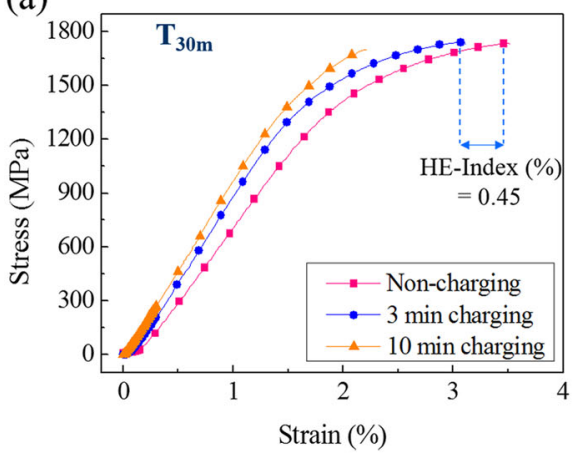

(b)

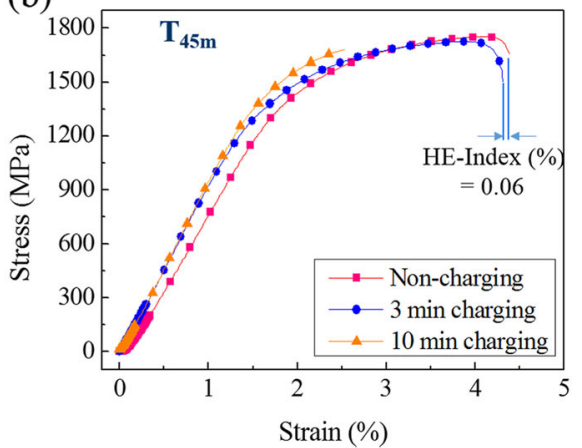

Fig. 6 SSRT curves of pre-charged N1 specimens which had been tempered for $30 \mathrm{~min}\left(\mathrm{~T}_{30 \mathrm{~m}}\right)$, and for $45 \mathrm{~min}\left(\mathrm{~T}_{45 \mathrm{~m}}\right)$, with a charging current density of $-1 \mathrm{~mA} \mathrm{~cm}^{-2}$ for 3 and $10 \mathrm{~min}$, respectively

tempering duration, as analyzed by EBSD kernel average misorientation (KAM). The distribution of KAM suggests that there was no significant variation in the dislocation density until the tempering duration was $60 \mathrm{~min}$. A significant decrease in elongation and typical intergranular cracking along the prior- $\gamma$ austenite grain boundaries under long $\mathrm{H}$-charging conditions (10 min) was observed clearly in the samples regardless of the tempering duration (Fig. 7a, b). On the other hand, it is interesting to note that a lower fraction of $\varepsilon-\mathrm{Fe}_{2.4} \mathrm{C}$ by the shorter tempering duration $(30 \mathrm{~min})$ results in a comparatively high $\mathrm{HE}$ index $(0.45)$ and typical intergranular cracking (Fig. 7c in contrast to Fig. 7d) under short $\mathrm{H}$-charging conditions (3 min), which is in accordance with the results reported by Zhu et al. ${ }^{23}$ Considering that once the $\varepsilon-\mathrm{Fe}_{2.4} \mathrm{C}$ was filled with $\mathrm{H}$-atoms under longer $\mathrm{H}$-charging period of $10 \mathrm{~min}$, it cannot be an effective $\mathrm{H}$-trap leading to slower diffusion kinetics of $\mathrm{H}$-atoms. A beneficial effect of $\varepsilon$ - $\mathrm{Fe}_{2.4} \mathrm{C}$ can only be highlighted under shorter $\mathrm{H}$-charging conditions. This suggests that $\mathrm{N} 3$ with a lower fraction of $\varepsilon-\mathrm{Fe}_{2.4} \mathrm{C}$ acting as a strong $\mathrm{H}$-trap can be comparatively susceptible to $\mathrm{HE}$ when it is exposed to near-neutral environments of a low $\mathrm{H}$-concentration under applied stress conditions.

These findings pave new ways for the development of much stronger automotive steels with superior resistance to corrosioninduced HE. For novel steel alloys, it is essential to optimize the use of $\mathrm{Ni}$ with an economical alloy design based on extremely minute quantities of $\mathrm{Ni}(0.6-0.8 \mathrm{wt} \%)$ because $\mathrm{Ni}$ has both beneficial and adverse effects on HE by controlling the kinetics of $\mathrm{H}$-uptake, formation of localized pitting, and fraction of $\mathrm{Fe}_{2.4} \mathrm{C}$ in the steel. In particular, the adverse effects of Ni-alloying were determined by exposing steel with a Ni content greater than $1 \mathrm{wt}$. $\%$ to neutral corrosive environments under an applied tensile stress.

This study also highlights the need to consider the corrosion behavior on the surface when evaluating $\mathrm{HE}$, which is in contrast to conventional test methods involving severe cathodic $\mathrm{H}$ charging and subsequent mechanical testing.

\section{METHODS}

The steel under investigation was reheated to $1200^{\circ} \mathrm{C}$ for $2 \mathrm{~h}$, and hotrolled and cold-rolled to $2 \mathrm{~mm}$ in thickness. The samples were then austenitized by heating to $930^{\circ} \mathrm{C}$ for $7 \mathrm{~min}$ and quenched in a mixture of oil and water. The quenched specimens were additionally tempered at $200^{\circ} \mathrm{C}$ for $45 \mathrm{~min}$.

After mechanical polishing, the elemental distribution on the surfaces of the bare steels (N1 and N3) was analyzed by AES. EIS was conducted over the frequency range, $0.01 \mathrm{~Hz}$ to $100.000 \mathrm{~Hz}$, with a $10 \mathrm{mV}$ amplitude sinusoidal voltage applied at $-50 \mathrm{mV}$ vs. OCP. The test electrolyte for the EIS test was a Walpole solution of $0.2 \mathrm{M} \mathrm{CH}_{3} \mathrm{COONa}+0.185 \mathrm{M} \mathrm{HCl}$ with an initial $\mathrm{pH}$ of 3.5. The $\mathrm{H}$-uptake and diffusion kinetics in the specimens were examined using an electrochemical permeation technique (EPT). ${ }^{43,44}$ This technique involves the diffusion of $\mathrm{H}$-atoms generated on one side of a steel membrane by galvanostatic polarization with $-1 \mathrm{~mA} \mathrm{~cm}^{-2}$ in $3.5 \%$ $\mathrm{NaCl}+0.3 \% \mathrm{NH}_{4} \mathrm{SCN}$ (hereinafter called a neutral charging sol.), and the $\mathrm{H}-$ permeation flux was evaluated by measuring the $\mathrm{H}$-oxidation current on the other side of a steel membrane electroplated with palladium to which 

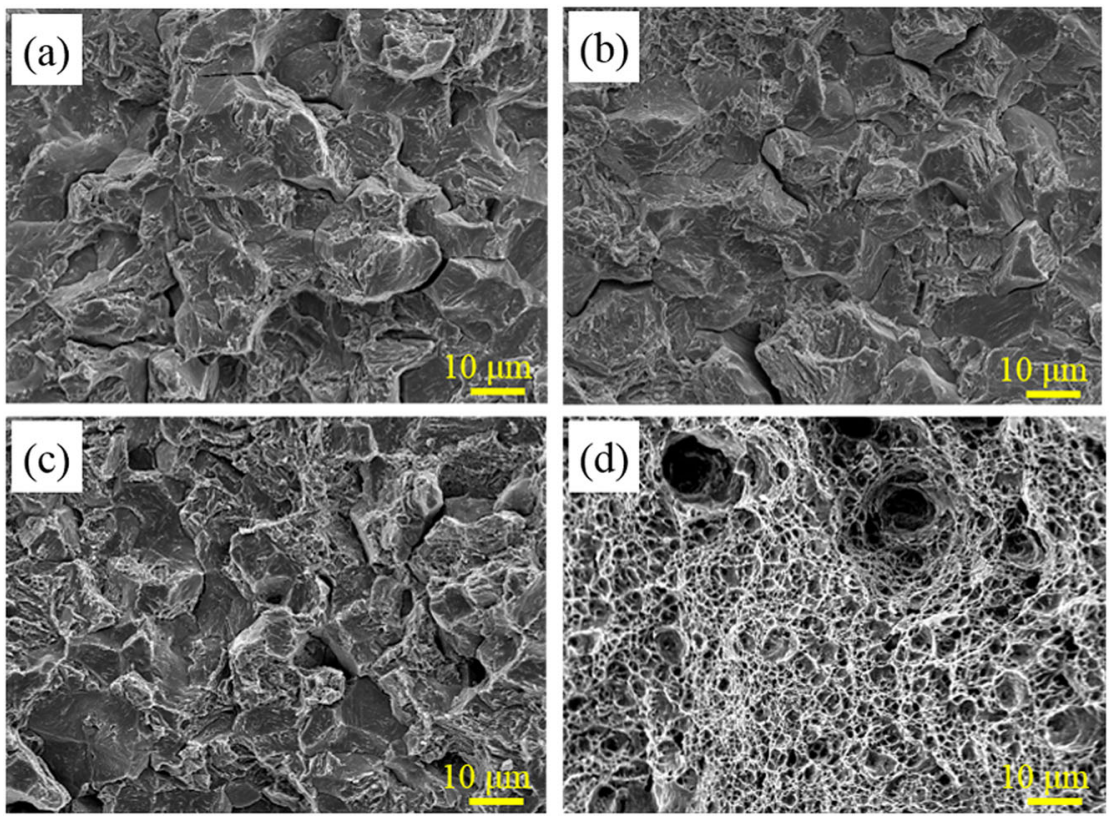

Fig. 7 Fracture surfaces after SSRT of pre-charged N1 which had been tempered (a) for 30 min, with a charging current density of $-1 \mathrm{~mA} \mathrm{~cm}^{-2}$ for $10 \mathrm{~min}$, (b) for $45 \mathrm{~min}$, with a charging current density of $-1 \mathrm{~mA} \mathrm{~cm}{ }^{-2}$ for $10 \mathrm{~min}$, (c) for $30 \mathrm{~min}$, with a charging current density of $-1 \mathrm{~mA}$ $\mathrm{cm}^{-2}$ for $3 \mathrm{~min}$, (d) for $45 \mathrm{~min}$, with a charging current density of $-1 \mathrm{~mA} \mathrm{~cm}{ }^{-2}$ for $3 \mathrm{~min}$, respectively

a constant anodic potential of $270 \mathrm{mV}_{\mathrm{SCE}}$ was applied. The detailed experimental procedure is reported elsewhere. ${ }^{40,45}$ After the experiment, the apparent $\mathrm{H}$-diffusivity $\left(D_{\text {app }}\right)$ was determined using the breakthrough method, which is expressed as follows:

$D_{\text {app }}=L^{2} /\left(15.3 \times t_{\mathrm{bt}}\right)$,

where $t_{b t}$ is the time needed for $\mathrm{H}$ to begin arriving at the detection side, and $L$ is the thickness of the steel membrane.

An immersion test was performed to evaluate the long-term corrosion behaviors on the surfaces, and to measure the weight loss. For the weight loss measurement, the specimens, $50 \mathrm{~mm}$ in width, $60 \mathrm{~mm}$ in length, and $1 \mathrm{~mm}$ in thickness, were cleaned with acetone and weighed in an analytical balance to a precision of $0.0001 \mathrm{~g}$. After immersion in a $3.5 \%$ $\mathrm{NaCl}$ solution for four weeks, the specimens were cleaned ultrasonically in ethanol for 1-2 min to remove the corrosion products completely, and dried for $1 \mathrm{~min}$. The specimens were weighed again in the same analytical balance. The difference between the initial and final weights divided by the initial areas was the weight loss. The cross-sectional images of the scale formed on the steel surfaces after the immersion test were also obtained. Prior to the observation, the samples were prepared using a focused ion beam. The resulting cross-sectional parts were then analyzed by TEM and energy dispersive spectroscopy (EDS). In addition, linear polarization resistance measurements were conducted in a $3.5 \% \mathrm{NaCl}$ solution after pre-immersion for $3 \mathrm{~h}$ in solution. For these measurements, the samples were polarized dynamically from approximately $-20 \mathrm{mV}$ to $20 \mathrm{mV}$ with respect to the OCP at a scan rate of $0.2 \mathrm{mV} \mathrm{s}^{-1}$.

The resistance of the samples to corrosion-induced HE was evaluated by providing corrosive environments and dynamic tensile loading condition, simultaneously. For this, a slow strain rate test (SSRT) at a strain rate of $10^{-6} \mathrm{~s}^{-1}$ was performed in two types of aqueous solution: Walpole solution and neutral charging sol. after $6 \mathrm{~h}$ pre-exposure to the solution at the OCP. The $R_{p}$ values were obtained by EIS shortly before fracture of each specimen by the SSRT. The other experimental conditions were the same as those of the EIS measurements for bare steels described above. In addition, thermal desorption analysis of hydrogen was conducted to measure the diffusible hydrogen content in the steel shortly before fracture by the SSRT. The specimens were heated from 25 to $270^{\circ} \mathrm{C}$ at a heating rate of $200^{\circ} \mathrm{C} / \mathrm{h}$.

For a mechanistic study, the surface morphologies of $\mathrm{N} 1$ and N3 obtained after immersion in the two types of solution for $15 \mathrm{~h}$ were observed by FE-SEM. For another mechanistic study of the effects of $\mathrm{Fe}_{2.4} \mathrm{C}$ on $\mathrm{HE}$, a SSRT at a strain rate of $10^{-5} \mathrm{~s}^{-1}$ was also conducted on two precharged specimens that had been tempered at $200^{\circ} \mathrm{C}$ for 30 and $45 \mathrm{~min}$, respectively, with a charging current density of $-1 \mathrm{~mA} \mathrm{~cm}^{-2}$ for 3 and
10 min, respectively. After the SSRT, the fracture surfaces were observed by FE-SEM.

\section{DATA AVAILABILITY}

The data that support the findings of this study are available from the corresponding author upon reasonable request.

\section{ACKNOWLEDGEMENTS}

The ultrastrong GIGA STEEL was produced by POSCO. This research was supported partly by the National Research Foundation of Korea (NRF) grant funded by the Korea government (MSIT) (No. 2019R1C1C1005007).

\section{AUTHOR CONTRIBUTIONS}

S.J.K. designed the study and wrote the paper; E.H.W., J.S.P. and S.M.R. performed the electrochemical experiments; S.J.K. and D.W.Y. analyzed the data; H.G.S. designed and produced the samples. All authors discussed the results and commented on the manuscript.

\section{ADDITIONAL INFORMATION}

Supplementary information accompanies the paper on the npj Materials Degradation website (https://doi.org/10.1038/s41529-019-0074-5).

Competing interests: The authors declare no competing interests.

Publisher's note: Springer Nature remains neutral with regard to jurisdictional claims in published maps and institutional affiliations.

\section{REFERENCES}

1. Faderl, J. In Application of continuous galvanized steel in Europe: Driving forces and game changer: In International Conference on Zinc and Zinc Alloy Coated Steel Sheet, Tokyo, Japan 36-45 (2017).

2. Lovicu, G. et al. Hydrogen embrittlement of advanced high strength steels for automotive use: In International Conference on Super High-Strength Steels, Italy (2010).

3. Kim, S. H., Kim, H. \& Kim, N. J. Brittle intermetallic compound makes ultrastrong low-density steel with large ductility. Nature 518, 77-79 (2015). 
4. Foroulis, Z. A. \& Uhlig, H. H. Effect of cold-work on corrosion of iron and steel in hydrochloric acid. J. Electrochem. Soc. 111, 522-528 (1964).

5. Staicopolus, N. The role of cementite in the acidic corrosion of steel. J. Electrochem. Soc. 110, 1121-1124 (1963).

6. Lee, M. C. \& Simkovich, G. Electrical conduction behavior of cementite, $\mathrm{Fe}_{3} \mathrm{C}$. Metal. Trans. 18A, 485-486 (1987).

7. Farelas, F., Galicia, M., Brown, B., Nesic, S. \& Castaneda, H. Evolution of dissolution processes at the interface of carbon steel corroding in a $\mathrm{CO}_{2}$ environment studied by EIS. Corros. Sci. 52, 509-517 (2010).

8. Feilong, S., Xiaogang, L. \& Xuequn, C. Effect of carbon content and microstructure on corrosion property of new developed steels in acidic salt solutions. Acta Metall. Sin. 27, 115-123 (2014).

9. Chan, S. L. I. \& Charles, J. A. Effect of carbon content on hydrogen occlusivity and embrittlement of ferrite-pearlite steels. Mater. Sci. Tech. 2, 956-962 (2013).

10. Nagao, A., Hayashi, K., Oi, K. \& Mitao, S. Effect of uniform distribution of fine cementite on hydrogen embrittlement of low carbon martensitic steel plates. ISIJ Int. 52, 213-221 (2012).

11. So, K. H. et al. Hydrogen delayed fracture properties and internal hydrogen behavior of a Fe-18Mn-1.5Al-0.6C TWIP steel. ISIJ Int. 49, 1952-1959 (2009).

12. Bhadeshia, H. K. D. H. Prevention of hydrogen embrittlement in steels. ISIJ Int. 56, 24-36 (2016).

13. Johnson, H. H. \& Troiano, A. R. Crack initiation in hydrogenated steel. Nature 179 777 (1957).

14. Frappart, S. et al. Hydrogen solubility, diffusivity and trapping in a tempered Fe-C$\mathrm{Cr}$ martensitic steel under various mechanical stress states. Mater. Sci. Eng. A 534, 384-393 (2012).

15. Villalobos, J. C., Serna, S. A., Campillo, B. \& Martínez, E. L. Evaluation of mechanical properties of an experimental microalloyed steel subjected to tempering heat treatment and its effect on hydrogen embrittlement. Int. J. Hyd. Ene. 42, 689-698 (2017).

16. Guedes, D. et al. The influence of hydrogen flux on crack initiation in martensitic steels. Proce. Mater. Scie. 3, 2024-2029 (2014).

17. Krawczyk, J., Bala, P. \& Pacyna, J. The effect of carbide precipitate morphology on fracture toughness in low-tempered steels containing Ni. J. Microsc. 237, 411-415 (2010).

18. Jarvis, A. R. The effect of Nickel content on the environmental assisted cracking (EAC) behavior of low alloy steels in sour environments-A review. Int. J. Pres. Ves. Pip. 49, 271-307 (1992).

19. Kaneko, T. \& Ikeda, A. Influence of small amounts of nickel addition on sulfide stress cracking susceptibility in low alloy steel. Trans. Isij. 28, 575-577 (1988).

20. Beck, W., Bockris, J. O. 'M., Genshaw, M. A. \& Subramanyan, P. K. Diffusivity and solubility of hydrogen as a function of composition in Fe-Ni alloys. Metall. Trans. 2, 883-888 (1971).

21. Wilde, B. E., Kim, C. D. \& Turn, J. C. The influence of noble metal additions on the sulfide corrosion performance of AISI 4130 steel. Corrosion 38, 515-524 (1982).

22. Speich, G. R. Tempering of low-carbon martensite. Trans. Metall. Soc. AIME 245 , 2553-2564 (1969).

23. Zhu, X. et al. Improved resistance to hydrogen embrittlement in a high-strength steel by quenching-partitioning-tempering treatment. Scr. Mater. 97, 21-24 (2015).

24. Nakagawa, Y., Tada, M., Kojima, K. \& Nakamaru, H. Effect of Nb contents on size of ferrite grains and $\mathrm{Nb}$ precipitates in ultra-low carbon steel for cans. ISIJ Int. $\mathbf{5 6}$ 1262-1267 (2016).

25. Xie, Z. J., Ma, X. P., Shang, C. J., Wang, X. M. \& Subramanian, S. V. Nano-sized precipitation and properties of a low carbon niobium micro-alloyed bainitic steel. Mater. Sci. Eng. A 641, 37-44 (2015).

26. Li, L., Song, B., Cheng, J., Yang, Z., Cai, Z. Effects of vanadium precipitates on hydrogen trapping efficiency and hydrogen induced cracking resistance in X80 pipeline steel. Inter. J. Hydrogen Energy 43, 17353-17363 (2018).

27. Turk, A., Martín, D. S., Rivera-Díaz-del-Castillo, P. E. J. \& Galindo-Nava, E. I. Correlation between vanadium carbide size and hydrogen trapping in ferritic steel. Scr. Mater. 152, 112-116 (2018)
28. Cheng, X. Y., Li, H. \& Cheng, X. B. Carbides and possible hydrogen irreversible trapping sites in ultrahigh strength round steel. Micron 103, 22-28 (2017).

29. Hong, G. W. \& Lee, J. Y. The interaction of hydrogen and the cementite-ferrite interface in carbon steel. J. Mater. Sci. 18, 271-277 (1983).

30. Johnson, D. L., Krauss, G., Wu, J. K. \& Tang, K. P. Correlation of microstructural parameters and hydrogen permeation in carbon steel. Metall. Trans. A 18 717-721 (1987)

31. Krawczyk, J., Bala, P. \& Pacyna, J. TEM studies of tempered structural steels with Ni. J. Achie. Mater. Manuf. Eng. 21, 59-62 (2007).

32. Hui, W., Zhang, H., Zhang, Y., Zhao, X. \& Shao, C. Effect of nickel on hydrogen embrittlement behavior of medium carbon high strength steels. Mater. Sci. Eng. A 674, 615-625 (2016).

33. Hwang, E. H., Ryu, S. M. \& Kim, S. J. Mechanistic studies on the hydrogen evolution and permeation of ultra-strong automotive steel in neutral chloride environments. Korean J. Mater. Res. 28, 428-434 (2018).

34. Wei, G. et al. Heterogeneous activation of Oxone by substituted magnetites $\mathrm{Fe}_{3}$ ${ }_{-} \mathrm{M}_{\mathrm{x}} \mathrm{O}_{4}(\mathrm{Cr}, \mathrm{Mn}, \mathrm{Co}, \mathrm{Ni})$ for degradation of Acid Orange II at neutral $\mathrm{pH}$. J. Mole. Cata. A: Chem. 398, 86-94 (2015).

35. Shimotsusa, M., Ibaraki, N., Ikeda, T. \& Nakayama, T. Wire rod for suspension spring with excellent corrosion fatigue life. Wire J. Int. 31, 78-83 (1998).

36. Kimura, M., Suzuki, T., Shigesato, G., Kihira, H. \& Suzuki, S. Characterization of nanostructure of rusts formed on weathering steel. ISIJ Int. 42, 1534-1540 (2002).

37. Kim, S. J., Hong, S. G. \& Oh, M. S. Effect of metallurgical factors on the pitting corrosion behavior of super austenitic stainless steel weld in an acidic chloride environment. J. Mater. Res. 32, 1343-1350 (2017).

38. Tsuru, T., Huang, Y., Ali, M. R. \& Nishikata, A. Hydrogen entry into steel during atmospheric corrosion process. Corrs. Sci. 47, 2431-2440 (2005).

39. Li, S., Akiyama, E., Shinohara, T., Matsuoka, K. \& Oshikawa, W. Hydrogen entry behavior into iron and steel under atmospheric corrosion. ISIJ Int. 53, 1062-1069 (2013).

40. Kim, S. J., Yun, D. W., Jung, H. G. \& Kim, K. Y. Determination of hydrogen diffusion parameters of ferritic steel from electrochemical permeation measurement under tensile loads. J. Electrochem. Soc. 161, E173-E181 (2014).

41. Kim, S. J., Yun, D. W., Jung, H. G. \& Kim, K. Y. Numerical study on hydrogen permeation of ferritic steel evaluated under constant load. Mater. Sci. Tech. 33 149-161 (2016)

42. Kim, S. J. Metallurgical evidence of stress induced hydrogen diffusion and corresponding crack nucleation behaviors of high-strength ferritic steel used in sour environment (manuscript in preparation).

43. Devanathan, M. A. V. \& Stachurski, Z. The absorption and diffusion of electrolytic hydrogen in palladium. Proc. R. Soc. A 270, 90-102 (1962).

44. ISO standard 17081, Method of measurement of hydrogen permeation and determination of hydrogen uptake and transport in metals by an electrochemical technique. https://www.iso.org/standard/64514.html (2014).

45. Kim, S. J. \& Kim, K. Y. Electrochemical hydrogen permeation measurement through high-strength steel under uniaxial tensile stress in plastic range. Scr. Mater. 66, 1069-1072 (2012). Attribution 4.0 International License, which permits use, sharing, adaptation, distribution and reproduction in any medium or format, as long as you give appropriate credit to the original author(s) and the source, provide a link to the Creative Commons license, and indicate if changes were made. The images or other third party material in this article are included in the article's Creative Commons license, unless indicated otherwise in a credit line to the material. If material is not included in the article's Creative Commons license and your intended use is not permitted by statutory regulation or exceeds the permitted use, you will need to obtain permission directly from the copyright holder. To view a copy of this license, visit http://creativecommons. org/licenses/by/4.0/.

(c) The Author(s) 2019 